УДК 621.396 .96

\title{
ОЦЕНКА ПОТЕНЦИАЛЬНОЙ ЭФФЕКТИВНОСТИ МЕЖПЕРИОДНОЙ ОБРАБОТКИ КОГЕРЕНТНОЙ ПАЧКИ РАДИОИМПУЛЬСОВ НА ФОНЕ ПАССИВНЫХ ПОМЕХ В ИМПУЛЬСНО-ДОПЛЕРОВСКИХ РЛС СО СРЕДНЕЙ ЧАСТОТОЙ ЗОНДИРОВАНИЯ
}

\author{
В. П. РЯБУХА ${ }^{1}$, В. В. ЦИСАРЖ ${ }^{1}$, Е. А. КАТЮШИН ${ }^{1}$, В. И. ЗАРИЦКИЙ ${ }^{2}$ \\ ${ }^{1}$ Научно-исследовательский институт радиолокационных систем «Квант-Радиолокаичя», \\ Украина, Киев, 03150, ул. Деловая, 5 \\ ${ }^{2}$ Харьковский национальный университет радиоэлектроники, \\ Украина, Харьков, 61166, пр-т Науки, 14
}

\begin{abstract}
Аннотация. Анализируется потенциальная эффективность оптимальной межпериодной обработки (МПО) когерентных пачек радиоимпульсов, отраженных от точечных воздушных целей, на фоне мощных пассивных помех (ПП) при работе РЛС в импульсно-доплеровском (ИД) режиме со средней частотой зондирования при неоднозначных измерениях дальности и скорости цели. Эта эффективность сравнивается с эффективностью МПО при работе РЛС в когерентно-импульсном режиме. Анализ проводится при постоянном и переменном интервалах зондирования, когда временная протяженность зоны источников ПП как меньше, так и больше интервала зондирования в ИД РЛС, т.е. при отсутствии и наличии наложений пассивных помех из различных участков дальности. Анализируются случаи полного совпадения параметров накладывающихся ПП и при различных радиальных скоростях равномощных слоев ПП, а также случаи наложения неравномощных слоев ПП, мощности которых обратно пропорциональны квадрату расстояния от их источников. Дополнительно учитывается вобуляция интервалов зондирования сигналов.
\end{abstract}

Ключевые слова: импульсно-доплеровская РЛС; средняя частота зондирования; неоднозначность измерения дальности; неоднозначность измерения скорости; пассивная помеха; отношение сигнал/(помеха + шум)

\section{ВВЕДЕНИЕ}

РЛС контроля воздушного пространства и управления воздушным движением решают свои информационные задачи в условиях помех, в частности, маскирующих пассивных помех (ПП) - мешающих отражений различной физической природы. Пример их воздействия показан на экране ИКО действующей РЛС 23-см диапазона (рис. 1). Видно, что значительная часть площади экрана «засвечена» ПП, на фоне которых обнаружить более слабый полезный сигнал от воздушной цели без специальных мер практически невозможно.

Защите РЛС от пассивных помех, в первую очередь - методам скоростной селекции движущихся целей (СДЦ) на их фоне, уделено огромное внимание в научно-технической литературе [1-17]. Они повсеместно применяются в РЛС различных видов и назначений, в частности, в

- когерентно-импульсных (КИ) обзорных РЛС с низкой частотой зондирования (НЧЗ) при однозначных измерениях дальности и неоднозначных измерениях скорости цели $[1,3-10$, 16]. Их также называют РЛС с СДЦ [3-6];

- более дорогостоящих и сложных [4] импульсно-доплеровских (ИД) бортовых (самолетных) и наземных РЛС со средней частотой зондирования (СЧЗ) при неоднозначных измерениях дальности и скорости цели, или с высо- 


\section{БИБЛИОГРАФИЧЕСКИЙ СПИСОК}

1. Ширман, Я. Д.; Багдасарян, С. Т.; Маляренко, А. С.; Леховицкий, Д. И.; и др. Радиоэлектронные системы. Основы построения и теория: Справочник. Под ред. Я. Д.Ширмана. М.: Радиотехника, 2007. 512 c.

2. Бакулев, П.А.; Степин, В.М. Методы и устройства селекиии движущихся иелей. М.: Радио и связь, 1986. 288 с.

3. Skolnik, M. I. Introduction to Radar Systems. New York: McGraw-Hill, 1962. 633 p.

4. Skolnik, M. I. Introduction to Radar Systems, 3rd ed. New York: McGraw-Hill, 2001. 774 p.

5. Skolnik M. I. Radar Handbook, 3rd ed. New York: McGraw-Hill, 2008. 1328 p.

6. Barton, D. K. Radar System Analysis and Modeling. Boston-London: Artech House, 2005. 546 p.

7. Васин, В. В.; Власов, О. В.; Григорин-Рябов, В. В.; Дудник, П. И.; Степанов, Б. М. Радиолокационные устройства (теория и принципы построения). М.: Сов. Радио, 1970. 680 с.

8. Литвинов, В. В. “Потенциальная и реальная эффективность когерентно-импульсных систем СДЦ в обзорных РЛС при однозначном измерении дальности,” Радиотехника, № 100, С. 158-173, 1996.

9. Литвинов, В.В. "Радиолокаторы систем контроля воздушного пространства: ретроспектива и современные проблемы интеграции и унификации," Прикладная радиоэлектроника, Т. 3, № 4, С. 61-74, 2004.

10. Литвинов, В.В. “Первые разработки корреляционных автокомпенсаторов пассивных помех (1964-1974 гг.) и проблематика СДЦ при низкой частоте посылок в обзорных РЛС," Прикладная радиоэлектроника, Т. 8, № 4, С. 461-468, 2009.

11. Lekhovytskiy, D. I. "Thirty years experience in development of adaptive lattice filters theory, techniques and testing in Kharkiv," in: Proc. of 2011 VIII Int. Conf. on Antenna Theory and Techniques, ICATT, 20-23 Sept. 2011, Kyiv, Ukraine. IEEE, 2011. DOI: 10.1109/ICATT. 2011.6170713 .

12. Lekhovytskiy, D. I.; Rachkov, D. S.; Semeniaka, A. V.; Atamanskiy, D. V.; Riabukha, V. P. "Quasioptimal algorithms for batch coherent signals interperiod processi- 
Оценка потенциальной эффективности межпериодной обработки когерентной пачки радиоимпульсов на фоне пассивных помех в импульсно-доплеровских РЛС со средней частотой зондирования

ng against background clutter," Proc. of Int. Radar Symp., 16-18 Jun 2014, Gdansk, Poland. IEEE, 2014, p. 25-30. DOI: $10.1109 /$ IRS.2014.6869195.

13. Кашаев, С. М.; Плужников, А. Д.; Рындык, А. Г. "Обнаружение сигналов в пассивных помехах при разделении обработки на пространственную и временную,” Радиотехника, № 4, С. 55-57, 1990.

14. Popov, D. I.; Smolskiy, S. M. "Estimation of the clutter correlation coefficient in radar systems," Infocommun. J., Vol. 8, No. 3, p. 8-12, 2016.

15. Xu, J.; Ren, L.; Fan, H.; Mao, E.; Liu, Q. “Clutter and range ambiguity suppression using diverse pulse train in pulse Doppler system," Sensors, Vol. 18, No. 7, p. 2326, 2018. DOI: $10.3390 / \mathrm{s} 18072326$.

16. Bystrov, N. E.; Zhukova, I. N.; Reganov, V. M.; Chebotarev, S. D. "Range and Doppler ambiguity elimination in coherent radar using quasicontinuous signa1s," J. Mech. Eng. Res. Developments, Vol. 40, No. 4, p. 562-571, 2017.

17. Xu, J.; Liao, G.; So, H. C. "Space-time adaptive processing with vertical frequency diverse array for range-ambiguous clutter suppression," IEEE Trans. Geosci. Remote Sensing, Vol. 54, No. 9, p. 5352-5364, 2016. DOI: $10.1109 /$ TGRS.2016.2561308.

18. Дудник, П. И.; Кондратенков, Г. С.; Татарский, Б. Г.; и др. Авиаиионные радиолокационные комплексы и системы. Под ред. П. И. Дудника. М.: Изд-во ВВИА, 2006. $1112 \mathrm{c}$.

19. Вовшин, Б. М.; Пушков, А. А.; Вылегжанин, И. С.; Павлюков, Ю. Б. "Различение эхо-сигналов в смеси отражений от метеообъектов на «однозначной» и «неоднозначной» дальностях в импульсных ДМРЛ," Труды XXVIII Всероссийского симпозиума «Радиолокационное исследование природных сред», 16-17 апреля 2013. Санкт-Петербург, 2013, С. 373-378.

20. Дженкинс, Г.; Ваттс; Д. Спектральный анализ и его приложения. Вып. 2. Пер. с англ. М.: Мир, 1972. $285 \mathrm{c}$.

21. Леховицкий, Д. И.; Кириллов, И. Г. “Моделирование пассивных помех импульсным РЛС на основе процессов авторегрессии произвольного порядка," Системи обробки інформаиї: Збірник наукових праць, № 3, C. 90-101, 2008.

22. Rachkov, D. S.; Lekhovytskiy, D. I.; Semeniaka, A. V.; Riabukha, V. P. "Statistical analysis of ground clutter and point targets impact on accuracy of weather echoes parameters estimation," Proc. of Int. Radar Symp.,
IRS-2015, 24-26 June 2015, Dresden, Germany. IEEE, 2015, p. 604-609. DOI: 10.1109/IRS.2015.7226400.

23. Lekhovytskiy, D. I.; Atamanskiy, D. V.; Riabukha, V. P.; Rachkov, D. S.; Semeniaka, A. V. "Combining target detection against the background of jamming signals and jamming signal DOA estimation," in: Proc. of 2015 Int. Conf. on Antenna Theory and Techniques, ICATT, 21-24 Apr. 2015, Kharkiv, Ukraine. IEEE, 2015, p. 36-40. DOI: 10.1109/ICATT.2015.7136 777.

24. Довиак, Р. Дж.; Зрнич, Д. С. Доплеровские радиолокаторы и метеорологические наблюдения. Пер. с англ. под ред. А. А. Черникова. Л.: Гидрометеоиздат, $1988.512 \mathrm{c}$.

25. Nathanson, F. E.; Reilly, J. P.; Cohen, M. N. Radar Design Principles. Signal Processing and the Environment, 2nd ed. New York: McGraw-Hill, 1999. 720 p.

26. Рыжков, А. В. “Метеорологические объекты и их радиолокационные характеристики," Зарубежная радиоэлектроника, № 4, С. 6-17, 1993.

27. Li, Z.-W.; Yang, Y.; Li, Y.-Z.; Li, C. "Radar clutter statistical characteristics and modeling," Proc. SPIE 10468, AOPC 2017: 3D Measurement Technology for Intelligent Manufacturing, AOPC 2017, 4-6 June 2017, Beijing; China. Beijing: AOPC, 2017, Vol. 10458, 104580F. DOI: $10.1117 / 12.2282507$.

28. Zhu, G.; Chen, Y.; Yin, H. "Analiysis of typical ground clutter statistical characteristics," Proc. of Int. Applied Computational Electromagnetics Society Symp., 1-4 Aug 2017, Suzhou, China. IEEE, 2017. URI: https://ie eexplore.ieee.org/document/8051907.

29. Capon, J. "High-resolution frequencywavenumber spectrum analysis," Proc. IEEE, Vol. 57, No. 8, p. 1408-1418, 1969. DOI: 10.1109/PROC.1969.72 $\underline{78}$.

30. Lekhovytskiy, D. I.; Shifrin, Y. S. "Statistical analysis of 'superresolving' methods for direction-of-arrival estimation of noise radiation sources under finite size of training sample," Signal Processing, Vol. 93, No. 12, p. 3382-3399, 2013. DOI: 10.1016/j.sigpro.2013. 03.008 .

31. Вовшин, Б. М.; Леховицкий, Д. И.; Жуга, Г. А.; Лаврукевич, В. В. “СДЦ в импульсных РЛС: 8. Особенности защиты сверхширокополосных РЛС от пассивных помех," Прикладная радиоэлектроника, Т. 10, № 4, C. 543-548, 2011. URI: http://openarchive. nure.ua/handle/document/4721. 